\title{
Mapa digital de solos: Uma proposta metodológica usando inferência fuzzy
}

\author{
Claudia C. Nolasco-Carvalho ${ }^{1}$, Washington Franca-Rocha ${ }^{2}$ \& José M. Ucha ${ }^{3}$
}

\begin{abstract}
RESUMO
Elaborou-se um mapa digital de solos de uma área na região de Mucugê, BA, com o objetivo de avaliar o uso de geotecnologias na cartografia de solos. A metodologia desenvolvida a partir do modelo de inferência para solos - SoLIM, requer o conhecimento prévio da área por um especialista em mapeamento e está alicerçada na equação dos fatores de formação do solo e no modelo de distribuição dos solos na paisagem. Os dados, advindos do Modelo Digital do Terreno - MDT, da vegetação e da geologia, foram associados ao conhecimento do pedólogo e integrados em ambiente SIG (Sistema de Informações Geográficas) sob inferência fuzzy. A modelagem por lógica fuzzy permitiu apontar as incertezas e transições da cobertura pedológica e gerou um mapa digital de solo que, quando comparado com o mapa convencional da área, mostrou menor generalização no domínio de espaços e parâmetros, ou seja, um refinamento da escala, porém a aplicabilidade da metodologia depende da validação de campo e da repetição em outras áreas.
\end{abstract}

Palavras-chave: sistema de informação geográfica, geotecnologias, mapeamento

\section{Digital soil map: A methodological proposal using fuzzy inference}

\begin{abstract}
A digital soil map was elaborated for an area in the region of Mucugê-BA using data integration derived from a digital elevation model (DEM) of the vegetation and geology that was associated with a soil scientist's knowledge and correlated in a GIS environment (Geography Information System) under fuzzy inference, as a methodological proposal. The methodology was developed and based on the soil-land inference model - SoLIM, on the soil factor equation and the soil-landscape model. The fuzzy logic is able to simulate the uncertainty and transitions that often appear in pedologic systems. The results show that the methodology allows the generation of digital soil maps with increased scale and to reduce soil classe generalizations in the space and parameter domain. However, this methodology is very dependent upon the soil expert's knowledge and accuracy of the data base. To verify the applicability of the methodology the repetition of the study is recommended in other areas and the validation done through field work.
\end{abstract}

Key words: geography information system, geotechnology - GIS, mapping

1 Departamento de Zootecnia/Escola Superior do Sertão, Br-316, 87.5km, Bairro São Vicente, CEP 57500-000, Santana do Ipanema, AL. Fone: (82) 3621-3749. E-mail: ccseko@esser.edu.br

2 Departamento de Ciências Exatas/UEFS, Br-116, 3 km. Campus Universitário, CEP 44030-460, Feira de Santana, BA. Fone: (75) 3224-8294. E-mail: wrocha@uefs.br 3 Departamento de Ciências Aplicadas/CEFET-BA, Rua Emídio dos Santos, Barbalho, CEP 40301-015. Salvador, BA. Fone: (71) 2101-9463. E-mail: ucha@cefetba.br 


\section{INTRODUÇÃO}

A cartografia de solos é imprescindível à conservação e ao gerenciamento dos recursos naturais; sua execução requer o conhecimento pedológico, a compilação de dados ambientais (clima, geologia, vegetação e relevo) e a análise e interpretação de imagens. Na fase inicial há confecção de um mapa preliminar com delineamento de unidades a partir de fotointerpretação e da sobreposição de dados ambientais, associados com base no conhecimento e experiência própria do especialista em levantamento de solos. A este mapa são agregadas informações obtidas após sucessivas investigações de campo que, por interação sistemática, possibilitam ao pedólogo capturar as relações entre os solos e as diferentes feições da paisagem, estabelecer a distribuição espacial e os limites entre unidades no mapa final.

A precisão e a eficácia desses levantamentos, entretanto, dependem da habilidade do pedólogo, que é limitada por dois principais fatores: pela técnica de cartografia baseada em polígonos e pelo processo manual de produção do mapa de solo (Zhu et al., 2001; Zhu, 1999; Zhu et al., 1997).

Com o advento da informática, o uso de geotecnologias, do SIG (sistema de informações geográficas) e de dados de MDT (modelos digital do terreno), vem crescendo e sugerindo novos caminhos e modelos que possibilitam o tratamento de grande quantidade de dados e informações indispensáveis aos mapeamentos realizados em ciência do solo.

Objetivando avaliar o uso de geotecnologias enquanto instrumento que agiliza a cartografia de solos, gerou-se o mapa digital de solos de uma área na região de Mucugê, Estado da Bahia, na escala 1: 100.000, a partir da integração de dados advindos do Modelo Digital do Terreno - MDT, da vegetação e da geologia, que foram associados ao conhecimento de pedólogos e correlacionados em ambiente SIG sob inferência fuzzy.

\section{MATERIAL E MÉTODOS}

\section{Localização e caracterização da área de estudo}

A área selecionada para estudo está inserida na Região da Chapada Diamantina, no estado da Bahia, mais especificamente no município de Mucugê, limitada geograficamente pelas coordenadas $13^{\circ} 00^{\prime}-13^{\circ} 15^{\prime} \mathrm{S}$ e $41^{\circ} 30^{\prime}-$ $41^{\circ} 20^{\prime} \mathrm{W}$ (Figura 1).

Inserida no planalto da Serra do Sincorá, a parte oeste da área compreende, geomorfologicamente, uma superfície aplainada com altitudes entre 1000 e $1200 \mathrm{~m}$. O relevo predominante é plano a suave ondulado, porém seccionado por vales escavados nas fraturas. Na parte leste, a Serra do Sincorá impõe uma brusca modificação da paisagem que apresenta feição montanhosa e altitudes entre 1600 a $1800 \mathrm{~m}$ (CPRM, 1994).

Prevalecem os Campos Gerais sobre superfícies de erosão e pediplanação geologicamente constituídas por rochas da Formação Tombador (arenitos, argilitos e conglomerados), do Grupo Paraguaçu (argilitos, siltitos e arenitos) e por co-

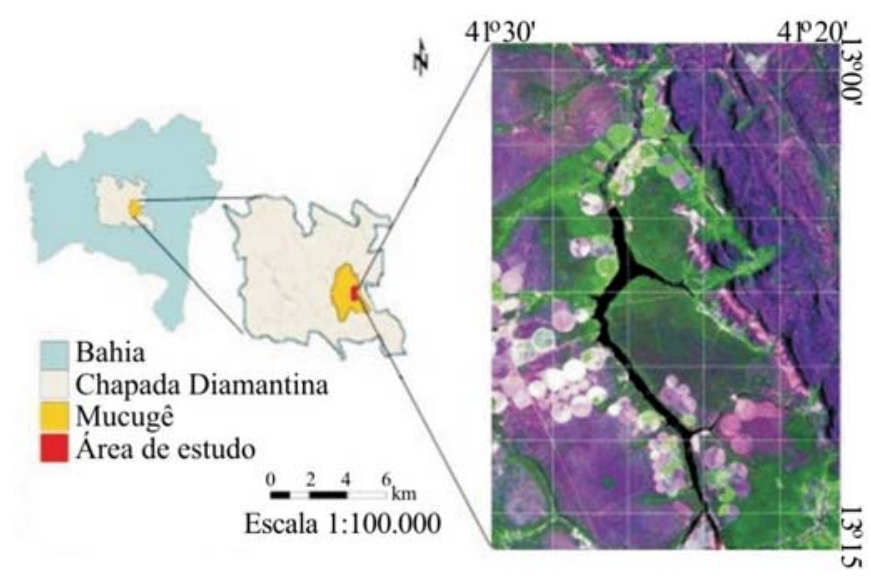

Figura 1. Localização geográfica da área de estudo

berturas residuais derivadas dos sedimentos do Grupo Paraguaçu. Essas coberturas dominam a parte ocidental da área e são essencialmente arenosas ou areno-argilosas. A oeste de Mucugê e ao longo do rio Paraguaçu, essas superfícies aplainadas se encontram laterizadas (Bigarella at al., 1994; CPRM, 1990).

O clima da região é tropical sub-quente a sub-úmido. A pluviosidade e a temperatura média anual estão entre 800$1200 \mathrm{~mm}$ e 20 a $24^{\circ} \mathrm{C}$, respectivamente, com variações decorrentes das diferenças altimétricas. O excedente hídrico é de 100 e $300 \mathrm{~mm}$ (SEI, 1998).

A vegetação primária remanescente apresenta-se sob a forma de mosaicos irregulares com variações fisionômicas bruscas em seu domínio, associadas às diferentes épocas e intensidade das intervenções antrópicas. Destacam-se na área: Savana Gramíneo-Lenhosa, Savana Parque e Savana Arbórea Aberta, o Refúgio Ecológico Montano e a Floresta Estacional Decidual Montana. Na parte central da área há domínio de vegetação de transição entre a Savana e a Floresta (Brasil, 1976; FIBGE, 1988).

\section{Base de dados}

A metodologia requer o conhecimento prévio da área de estudo pelo especialista em cartografia de solos condição que, aliada à existência de informações auxiliares (dados sobre fatores de formação do solo), constituiu os critérios para a seleção da área de estudo. O método proposto está sintetizado no diagrama da Figura 2, que mostra o uso de novas tecnologias alicerçadas na equação dos fatores de formação do solo (Jenny, 1961), e no modelo de distribuição dos solos na paisagem (Hudson, 1992).

A base cartográfica constou de: i) MDT advindos do sensor SRTM (Shuttle Radar Topography Mission); ii) Mapas temáticos na escala 1:100.00 de Geologia (CPRM, 1990); iii) Vegetação (FIBGE, 1988) e iv) Mapa de solo (FIBGE, 1988).

Utilizou-se para o processamento das informações em ambiente SIG, os aplicativos ArcGis 8.3 (ESRI, 1999a) com a extensão Spatial Analyst (ESRI, 1999b) e ARCSDM 2 Spatial Data Modeller 2 Extension para ArcMap 8.3 (Sawatzky et al., 2004).

A metodologia preconiza a validação final do mapa digital em campo, porém neste trabalho o mapa convencional 


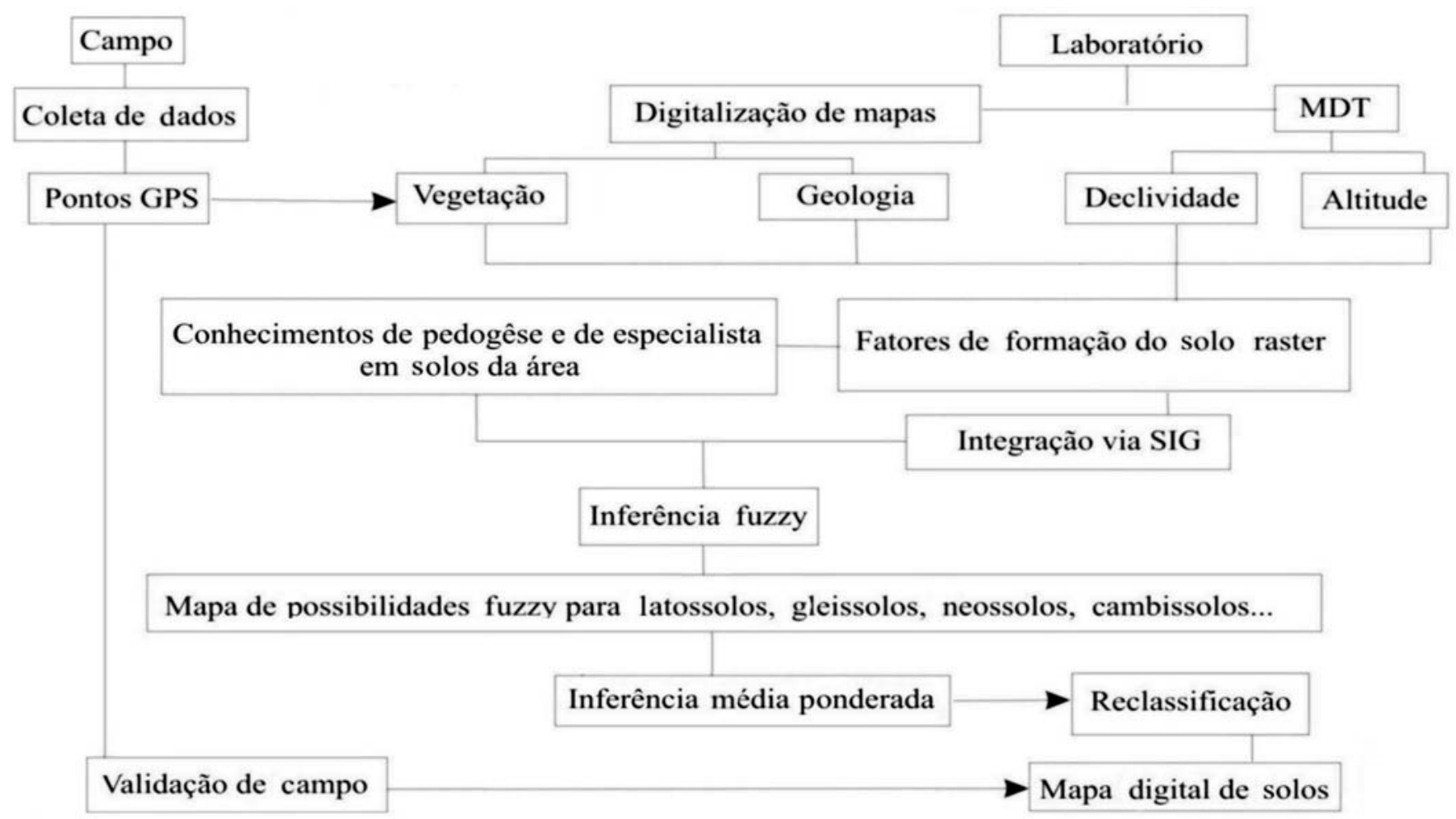

Figura 2. Fluxograma metodológico

do FIBGE (1988) foi utilizado como "verdade de campo" para comparação dos resultados obtidos. Os dados analógicos de geologia e vegetação, necessários à construção do banco de dados digital da área, foram capturados por escanerização, registrados, vetorizados e transformados em mapas raster com reamostragem para pixel de $30 \mathrm{~m}$. Visando compatibilizar a base cartográfica e o mapa de solo usado para fins comparativos, adotou-se o sistema de projeção plana Universal Transversa de Mercator (UTM) e o Datum Córrego Alegre.

As informações sobre o relevo, um dos principais fatores de formação do solo, foram geradas através do Modelo Digital do Terreno (MDT), sendo dele derivados os mapas de declividade (Figura 3) e de altitude (Figura 4).

\section{Sistematização e integração das informações sob inferência fuzzy}

O pedólogo, ao efetuar um levantamento de solos relaciona, mentalmente, dados ambientais espaciais (geologia, relevo, vegetação e clima, dentre outros), para estabelecer um padrão de distribuição das unidades de solo em uma área; logo, a integração de dados de fontes variadas no mapeamento de solos é tarefa moldada para sistemas de informações geográficas.

Os projetos desenvolvidos em SIG apresentam, como principal proposta, a combinação de dados espaciais com o objetivo de descrever e analisar interações, de modo a fazer previsões através de modelos prospectivos empíricos e fornecer apoio para a definição de classes, unidades ou sítios de interesse.

A técnica fuzzy tem sido intensamente utilizada em tra-

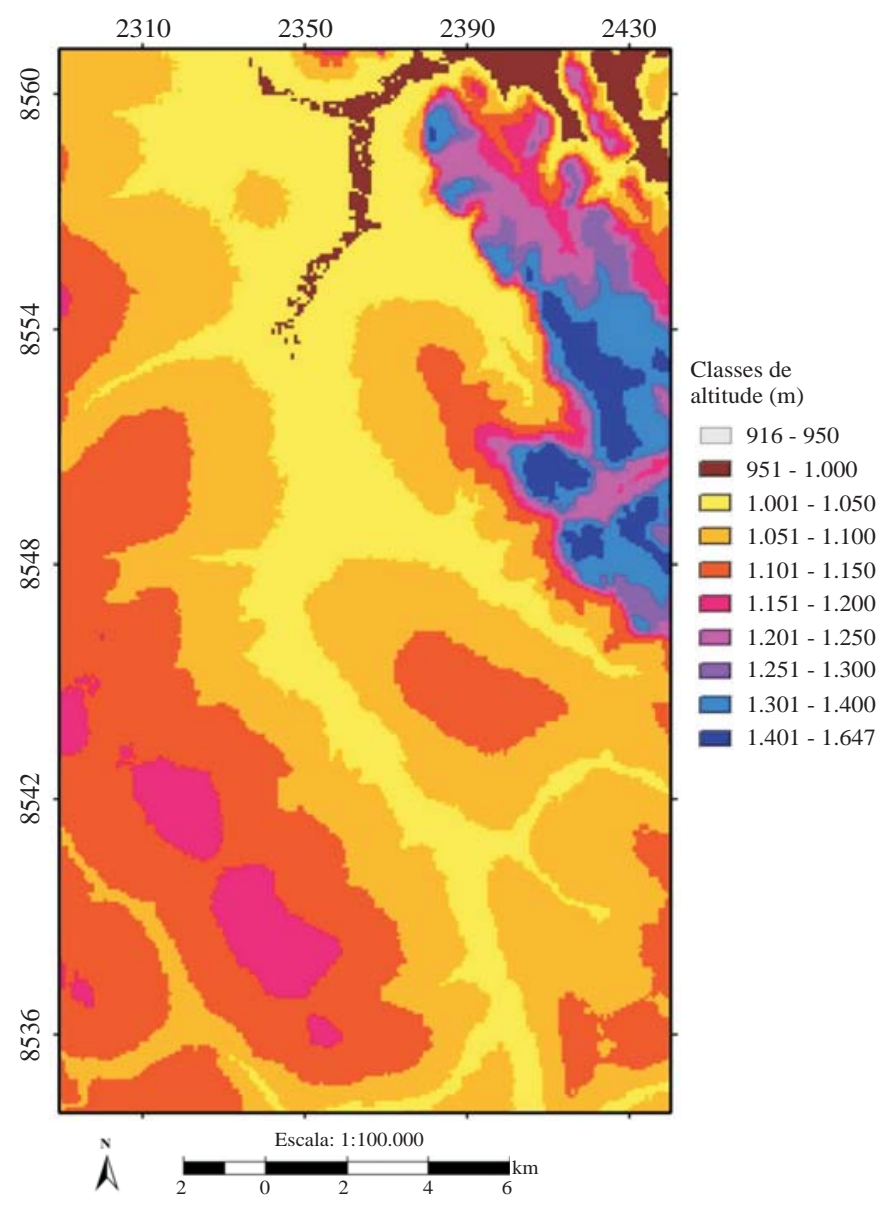

Fonte: extraído de MDT SRTM / S14 Datum Córrego Alegre 24S Figura 3. Mapa de altitude da região de Mucugê 


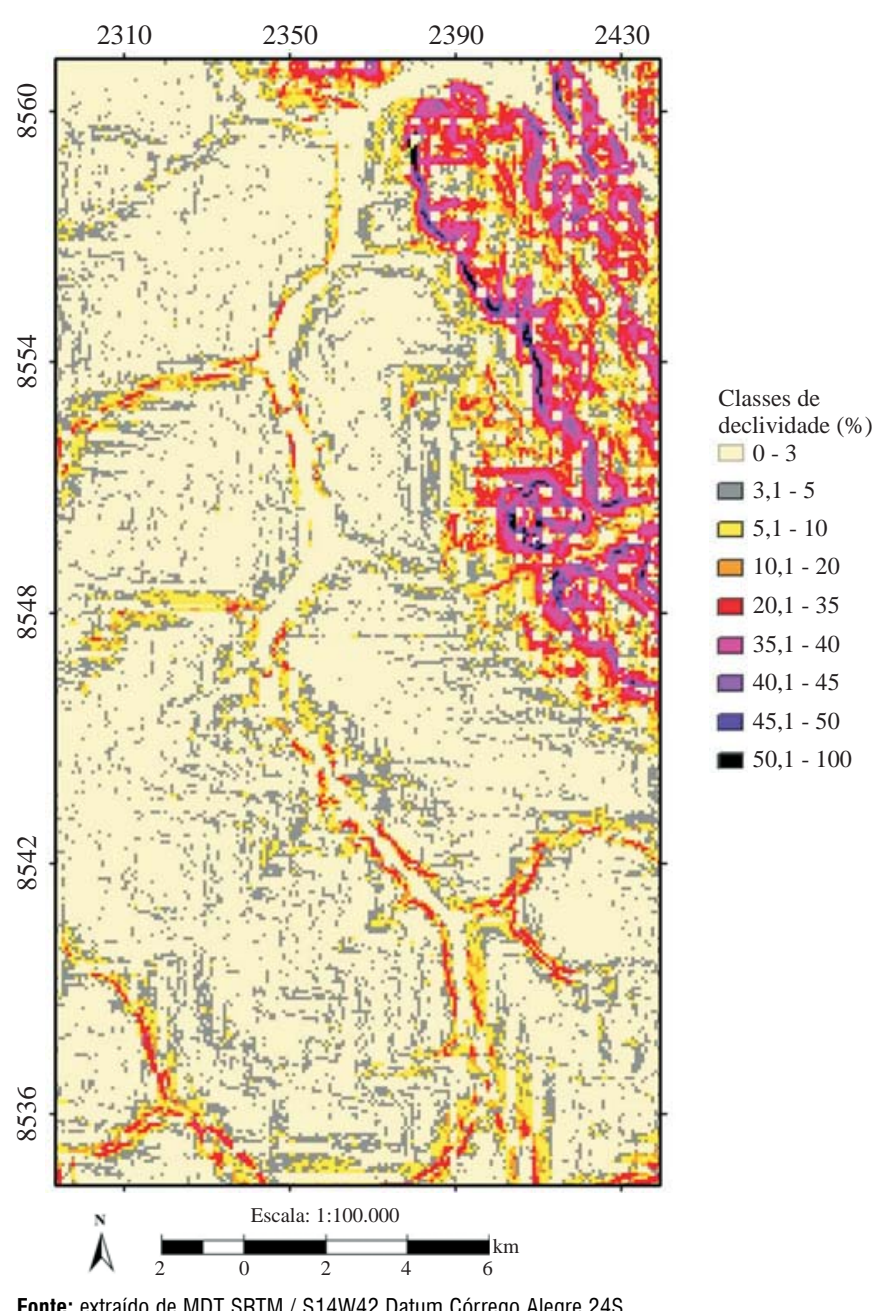

Fonte: extraído de MDT SRTM / S14W42 Datum Córrego Alegre 24S

Figura 4. Mapa de declividade da região de Mucugê

balhos de inferência espacial e, quando comparada com o modelamento convencional, tem a prerrogativa de não forçar os especialistas a definirem regras dicotômicas rígidas com contatos normalmente artificiais, que diminuem a habilidade de articular eficientemente soluções para problemas complexos, tão comuns em processos naturais (Tanscheit, 2006). As características intrínsecas da lógica fuzzy a tornam capaz de incorporar tanto o conhecimento objetivo (a partir de dados numéricos) quanto o conhecimento subjetivo (a partir de informações lingüísticas).

A modelagem por lógica fuzzy permite simular, através do uso de possibilidades, as incertezas e transições tão comuns aos sistemas pedológicos, que é feita correlacionando-se o grau de certeza à experiência e ao conhecimento acumulados; assim, a atribuição dos pesos às possibilidades de ocorrência das classes de solo em determinada área, é totalmente controlada pelo julgamento subjetivo de especialista experiente e que detenha um conhecimento profundo sobre a área de estudo (um pedólogo com experiência em levantamentos, por exemplo). Este tipo de modelagem faz parte da categoria denominada "baseada no conhecimento" e se apresenta como alternativa para operacionalizar os levantamentos de solo.

\section{RESULTADOS E DISCUSSÃO}

\section{Atribuição de valores fuzzy às classes dos mapas temáticos e obtenção do mapa de evidências fuzzy para as unidades de solo}

Para proceder à modelagem sob inferência fuzzy, é necessário que os mapas temáticos (fatores de formação do solo), sejam representados por uma função nebulosa; na prática, isto significou elaborar, para as unidades de solo predefinidas, uma tabela de atributos conferindo-se, para cada classe dos mapas temáticos (geologia, vegetação, altitude e declividade), valores entre 0 e 1 ; estes valores constituem o peso que a classe tem e foram determinados de forma subjetiva; por sua vez eles caracterizam o grau de importância de cada classe do mapa temático no controle da definição do tipo de solo (Tabela 1). Os valores máximos do grau de pertinência de cada conjunto fuzzy, atribuído a cada mapa, controlam também o peso relativo de cada evidência (fator de formação do solo) no processo de modelagem.

Alicerçados na equação dos fatores de formação do solo de Jenny (1961) no modelo de distribuição dos solos na paisagem de Hudson (1992) e no conhecimento da área obtido através de trabalhos anteriores especificou-se, para a área, a ocorrência de sete classes de solo: Latossolo Vermelho-Amarelo; Argissolo Acinzentado, Espodossolo Húmico, Gleissolo Húmico; Cambissolo Háplico; Neossolo Litolico e Neossolo Flúvico.

A atribuição dos pesos a cada classe dos mapas (fator de formação considerado), foi embasada na premissa de que a evolução dos solos é condicionada pelo grau de combinação dos fatores de formação do solo; esta interação determina a dinâmica dos processos pedogenéticos e, conseqüentemente, origina diferentes classes de solos.

Na Tabela 1 podem ser vistos os graus de pertinência atribuídos às classes de vegetação, geologia, declividade e altitude que foram utilizadas para gerar mapas fuzzy desses mesmos fatores para as classes de solo predefinidas.

Os valores foram arbitrários e seguiram unicamente o conhecimento do especialista em solo. A facilidade de edição das tabelas possibilitou o exame dos mapas de evidências para as classes de solos gerados a partir de diferentes proposições de operadores fuzzy e a definição na modelagem do operador lógico interseção (FuzzyAND), para obtenção dos mapas de evidências fuzzy para cada classe de solo; este operador produz estimativas conservadoras implicando, pedologicamente, na modelagem de associações de fatores diagnósticos, ou seja, na seleção mais rigorosa de áreas mais propícias à ocorrência de determinada classe de solo.

O exame da Figura 5, que esquematiza a obtenção do mapa de evidências fuzzy para Latossolos, permite melhor compreensão desta etapa do processo de modelagem; por exemplo, se a possibilidade de ocorrer Latossolo em um local (um pixel ou um polígono), tiver os valores $\mu \mathrm{A}=0,50$, $\mu \mathrm{B}=0,90$ e $\mu \mathrm{C}=0,30$ (respectivamente para os fatores geologia, vegetação e declividade), o mapa resultante assumirá o valor $\mu \mathrm{comb}=0,30$ neste mesmo local, deduzindo-se que somente onde os três mapas combinados possuam simultaneamente valores elevados se consideraria locais mais prováveis para a ocorrência de Latossolos. 
Tabela 1. Peso atribuído às classes dos mapas de fatores para Latossolo Vermelho-Amarelo; Argissolo Acinzentado, Espodossolo Húmico, Gleissolo Húmico; Cambissolo Háplico; Neossolo Litólico e Neossolo Flúvico

\begin{tabular}{|c|c|c|c|c|c|c|c|c|c|c|c|c|c|c|c|}
\hline \multicolumn{8}{|c|}{ Latossolo Vermelho-Amarelo } & \multicolumn{8}{|c|}{ Gleissolo Háplico } \\
\hline Geo & PC & Alt (m) & $P C$ & $\operatorname{Dec}(\%)$ & $P C$ & Veg & PC & Geo & PC & Alt (m) & PC & Dec $(\%)$ & PC & Veg & PC \\
\hline Qcob & 0,9 & $920-1000$ & 0 & $0-3$ & 0,8 & Sas & 0,8 & Qcob & 0,1 & $920-1000$ & 0,9 & $0-3$ & 0,8 & Sas & 0 \\
\hline Qlat & 0,7 & $1000-1040$ & 0 & $3-5$ & 0,9 & Saf & 0,7 & Qlat & 0,6 & $1000-1040$ & 0,9 & $3-5$ & 0,5 & Saf & 0,5 \\
\hline Qal & 0,2 & $1040-1100$ & 0 & $5-8$ & 0,8 & Sgs & 0,9 & Qal & 0,9 & $1040-1100$ & 0,2 & $5-8$ & 0,1 & Sgs & 0 \\
\hline Qtl & 0 & $1100-1200$ & 0,9 & $8-10$ & 0,7 & Sgf & 0,5 & Qtl & 0 & $1100-1200$ & 0,1 & $8-10$ & 0,1 & Sgf & 0,5 \\
\hline Ppfd & 0,6 & $1200-1250$ & 0,8 & $10-20$ & 0,3 & Sps & 0,9 & Ppfd & 0,5 & $1200-1250$ & 0,1 & $10-20$ & 10 & Sps & 0 \\
\hline Ppf & 0,8 & $1250-1300$ & 0,1 & $20-35$ & 0,1 & Spf & 0,8 & Ppf & 0,4 & $1250-1300$ & 0 & $20-35$ & 0 & Spf & 0,1 \\
\hline Ppdt & 0,8 & $1300-1400$ & 0 & $34-45$ & 0 & Vss/C & 0,7 & Ppdt & 0 & $1300-1400$ & 0 & $34-45$ & 0 & Vss/C & 0,1 \\
\hline Pppd & 0,8 & $1400-1500$ & 0 & $45-50$ & 0 & Vss/F & 0,9 & Pppd & 0,1 & $1400-1500$ & 0 & $45-50$ & 0 & Vss/F & 0,5 \\
\hline Pte & 0,2 & $1500-1600$ & 0 & $50-100$ & 0 & SN & 0,8 & Pte & 0 & $1500-1600$ & 0 & $50-100$ & 0 & SN & 0,6 \\
\hline Ptl & 0 & & & & & $\mathrm{Rm}$ & 0 & Ptl & 0 & & & & & $\mathrm{Rm}$ & 0,1 \\
\hline Ptt/e & 0 & & & & & & & $\mathrm{Ptt} / \mathrm{e}$ & 0 & & & & & & \\
\hline \multicolumn{8}{|c|}{ Argissolo Acinzentado } & \multicolumn{8}{|c|}{ Neossolo Flúvico } \\
\hline Geo & PC & Alt (m) & $\mathrm{PC}$ & $\operatorname{Dec}(\%)$ & PC & Veg & PC & Geo & PC & Alt (m) & PC & Dec (\%) & PC & Veg & PC \\
\hline Qcob & 0,5 & $920-1000$ & 0 & $0-3$ & 0,1 & Sas & 0,5 & Qcob & 0,3 & $920-1000$ & 0 & $0-3$ & 0,2 & Sas & 0,1 \\
\hline Qlat & 0,8 & $1000-1040$ & 0 & $3-5$ & 0,4 & Saf & 0,6 & Qlat & 0 & $1000-1040$ & 0 & $3-5$ & 0,1 & Saf & 0 \\
\hline Qal & 0,3 & $1040-1100$ & 0,7 & $5-8$ & 0,7 & Sgs & 0,5 & Qal & 0 & $1040-1100$ & 0,3 & $5-8$ & 0,1 & Sgs & 0,1 \\
\hline Qt1 & 0 & $1100-1200$ & 0,8 & $8-10$ & 0,8 & Sgf & 0 & Qtl & 0 & $1100-1200$ & 0,7 & $8-10$ & 0,1 & Sgf & 0 \\
\hline Ppfd & 0,6 & $1200-1250$ & 0,6 & $10-20$ & 0,9 & Sps & 0 & Ppfd & 0 & $1200-1250$ & 0,6 & $10-20$ & 0,5 & Sps & 0 \\
\hline Ppf & 0,8 & $1250-1300$ & 0,1 & $20-35$ & 0,5 & Spf & 0,5 & Ppf & 0,5 & $1250-1300$ & 0,5 & $20-35$ & 0,4 & Spf & 0 \\
\hline Ppdt & 0,6 & $1300-1400$ & 0 & $34-45$ & 0,1 & Vss/C & 0,7 & Ppdt & 0 & $1300-1400$ & 0,2 & $34-45$ & 0 & Vss/C & 0 \\
\hline Pppd & 0,3 & $1400-1500$ & 0 & $45-50$ & 0 & Vss/F & 0,8 & Pppd & 0 & $1400-1500$ & 0 & $45-50$ & 0 & Vss/F & 0 \\
\hline Pte & 0 & $1500-1600$ & 0 & $50-100$ & 0 & SN & 0,7 & Pte & 0 & $1500-1600$ & 0 & $50-100$ & 0 & SN & 0,1 \\
\hline Ptl & 0 & & & & & $\mathrm{Rm}$ & 0 & Ptl & 0 & & & & & $\mathrm{Rm}$ & 0,1 \\
\hline Ptt/e & 0 & & & & & & & $\mathrm{Ptt} / \mathrm{e}$ & 0 & & & & & & \\
\hline \multicolumn{8}{|c|}{ Cambissolo Háplico } & \multicolumn{8}{|c|}{ Neossolo Litólico } \\
\hline Geo & PC & Alt (m) & PC & Dec (\%) & PC & Veg & PC & Geo & PC & Alt (m) & PC & Dec (\%) & PC & Veg & PC \\
\hline Qcob & 0,4 & $920-1000$ & 0 & $0-3$ & 0,05 & Sas & 0,1 & Qcob & 0,2 & $920-1000$ & 0,1 & $0-3$ & 0,3 & Sas & 0 \\
\hline Qlat & 0,6 & $1000-1040$ & 0 & $3-5$ & 0,1 & Saf & 0,2 & Qlat & 0 & $1000-1040$ & 0,3 & $3-5$ & 0,1 & Saf & 0 \\
\hline Qal & 0,2 & $1040-1100$ & 0,7 & $5-8$ & 0,3 & Sgs & 0,4 & Qal & 0,1 & $1040-1100$ & 0,3 & $5-8$ & 0,1 & Sgs & 0 \\
\hline Qtl & 0,1 & $1100-1200$ & 0,8 & $8-10$ & 0,5 & Sgf & 0 & Qtl & 0,9 & $1100-1200$ & 0,4 & $8-10$ & 0,2 & Sgf & 0,5 \\
\hline Ppfd & 0 & $1200-1250$ & 0,1 & $10-20$ & 0,7 & Sps & 0 & Ppfd & 0 & $1200-1250$ & 0,5 & $10-20$ & 0,4 & Sps & 0 \\
\hline Ppf & 0,1 & $1250-1300$ & 0,1 & $20-35$ & 0,6 & Spf & 0,2 & Ppf & 0 & $1250-1300$ & 0,8 & $20-35$ & 0,8 & Spf & 0 \\
\hline Ppdt & 0 & $1300-1400$ & 0 & $34-45$ & 0,1 & Vss/C & 0 & Ppdt & 0 & $1300-1400$ & 1 & $34-45$ & 0,9 & Vss/C & 0 \\
\hline Pppd & 0 & $1400-1500$ & 0 & $45-50$ & 0 & Vss/F & 0,2 & Pppd & 0,2 & $1400-1500$ & 1 & $45-50$ & 1 & Vss/F & 0 \\
\hline Pte & 0 & $1500-1600$ & 0 & $50-100$ & 0 & SN & 0,5 & Pte & 1 & $1500-1600$ & 1 & $50-100$ & 1 & SN & 0 \\
\hline Ptl & 0 & & & & & $\mathrm{Rm}$ & 0 & Ptl & 1 & & & & & $\mathrm{Rm}$ & 0,9 \\
\hline $\mathrm{Ptt} / \mathrm{e}$ & 0 & & & & & & & $\mathrm{Ptt} / \mathrm{e}$ & 0,9 & & & & & & \\
\hline \multicolumn{8}{|c|}{ Espodossolo Húmico } & \multicolumn{8}{|c|}{ Legenda } \\
\hline Geo & PC & Alt (m) & PC & Dec (\%) & PC & Veg & $P C$ & \multirow{12}{*}{\multicolumn{8}{|c|}{$\begin{array}{l}\text { Geo - geologia (Qcob - cobertura tércio-quaternária; Qlat -crosta quartzo- } \\
\text { ferruginosa; Qal - sedimentos arenoargilosos; Qtl - depósitos coluvionares; Ppfd } \\
\text { - arenitos seixosos, siltitos e argilitos; Ppf - arenitos avermelhados; Ppdt - arenitos } \\
\text { seixosos; Pppd - argilitos lilás e siltitos; Pte - arenito cinza; Ptl - arenito e } \\
\text { conglomerado; Ptt/e - microconglomerados, arenitos, argilitos e siltitos) } \\
\text { Alt - altitude } \\
\text { Veg - vegetação (Sas - Savana Arbórea s/ Floresta de Galeria; Saf - Savana Arbórea } \\
\text { c/ Floresta de Galeria; Sgs - Savana Gramíneo-Lenhosa s/ Floresta de Galeria; Sgf } \\
\text { - Savana Gramíneo-Lenhosa c/ Floresta de Galeria; Sps - Savana Parque s/ Floresta } \\
\text { de Galeria; Spf - Savana Parque c/ Floresta de Galeria; Vss/C - Vegetação } \\
\text { Secundária / Caatinga; Vss/F - Vegetação Secundária / Floresta Estacional Semi- } \\
\text { Decidual; SN - Contato Savana / Floresta Estacional; Rm - Refúgio Ecológico }\end{array}$}} \\
\hline$\overline{Q c o b}$ & 0,2 & $920-1000$ & 0,1 & $0-3$ & 0,9 & Sas & 0 & & & & & & & & \\
\hline Qlat & 0 & $1000-1040$ & 0,1 & $3-5$ & 0,8 & Saf & 0 & & & & & & & & \\
\hline Qal & 0,1 & $1040-1100$ & 0,1 & $5-8$ & 0,4 & Sgs & 0 & & & & & & & & \\
\hline Qt1 & 0 & $1100-1200$ & 0,4 & $8-10$ & 0 & Sgf & 0 & & & & & & & & \\
\hline Ppfd & 0,1 & $1200-1250$ & 0,4 & $10-20$ & 0 & Sps & 0 & & & & & & & & \\
\hline Ppf & 0,5 & $1250-1300$ & 0,5 & $20-35$ & 0 & Spf & 0 & & & & & & & & \\
\hline Ppdt & 0 & $1300-1400$ & 0,5 & $34-45$ & 0 & Vss/C & 0 & & & & & & & & \\
\hline Pppd & 0 & $1400-1500$ & 0,8 & $45-50$ & 0 & Vss/F & 0,3 & & & & & & & & \\
\hline Pte & 0,5 & $1500-1600$ & 0,8 & $50-100$ & 0 & SN & 0,2 & & & & & & & & \\
\hline Ptl & 0,2 & & & & & $\mathrm{Rm}$ & 0,9 & & & & & & & & \\
\hline $\mathrm{Ptt} / \mathrm{e}$ & 0,5 & & & & & & & & & & & & & & \\
\hline
\end{tabular}




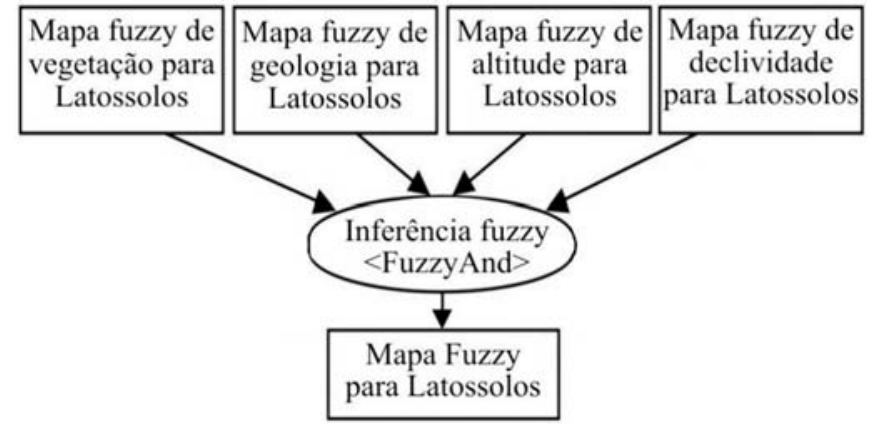

Figura 5. Fluxograma dos mapas de possibilidades fuzzy para as classes de solo

Para a combinação dos mapas temáticos foi utilizada a extensão do ArcSDM2 (Sawatzky et al., 2004) para ArcGis 8.3. Os mapas de possibilidades fuzzy, gerados para as classes de solos preestabelecidas foram, posteriormente, reclassificados; nesta etapa, foi associada a cada mapa de possibilidades, uma seqüência ordenada de potências de 2, cujo valor "0" (zero) sempre corresponde à ausência de ocorrência de determinada classe (unidade simples de mapeamento) e os valores intermediários (quando existentes) referentes à as- sociação de classes (associação de solos) ou zonas de transição entre classes de solo (Figura 6).

Esta técnica, denominada inferência média ponderada, aplicada para fusão dos sete mapas de evidências de classes de solo (Figura 7), permitiu que as simultaneidades fossem expressas por valores que pudessem ser reconhecidos, avaliados e correlacionados à realidade local e à "verdade", expressa no mapa de solos convencional usado como parâmetro para validação; trata-se de um artifício que evita resultados ambíguos, os quais poderiam conduzir a interpretações e a distribuição espacial incorretas dos solos na confecção do mapa digital de solos.

Os mapas de evidências fuzzy para as classes de solo (Figura 6), quando confrontados com o mapa de solos convencional (Figura 8), e apesar de apresentarem variações, mostraram semelhanças nos delineamentos individuais das unidades.

O mapa digital de solos (Figura 9), comparado com o mapa de solos convencional preexistente, apresenta similaridade nos limites entre as classes, porém há no mapa digital, novos delineamentos que, nas unidades do mapa de solos convencional, não encontram correspondência como, por exemplo, a unidade dos Latossolos Vermelho-Amarelos - LVA4.
A.

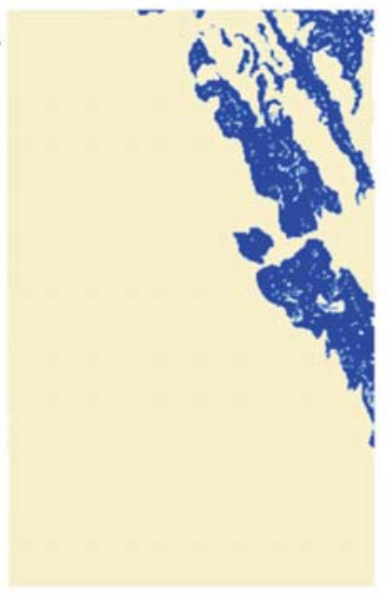

0

E.

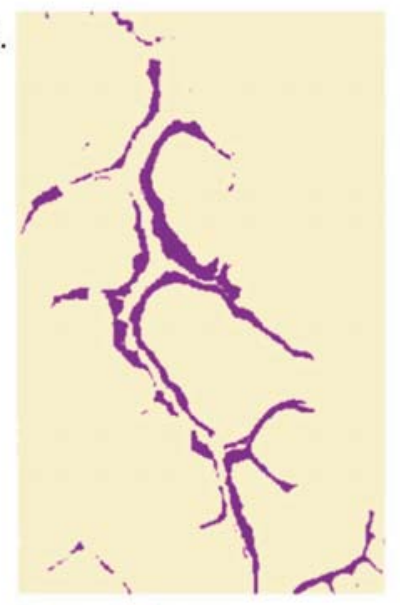

$0 \square 1.024$
B.

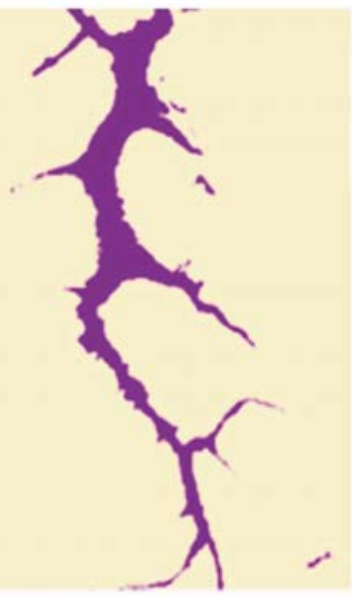

$0 \square 64$

F.

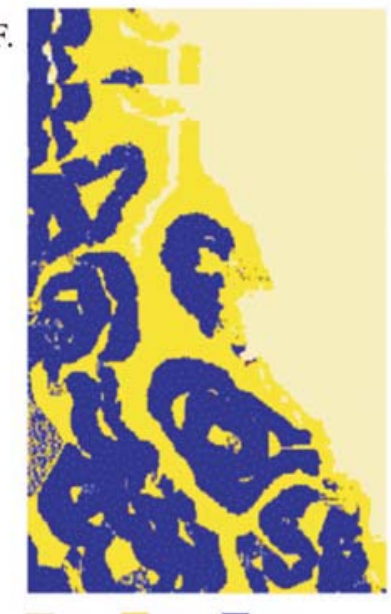

C.

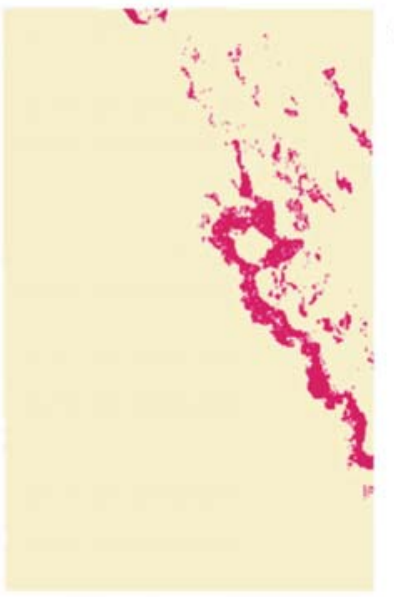

0

256

G.

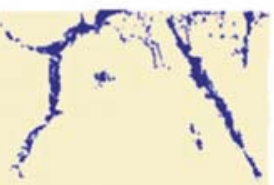

D.

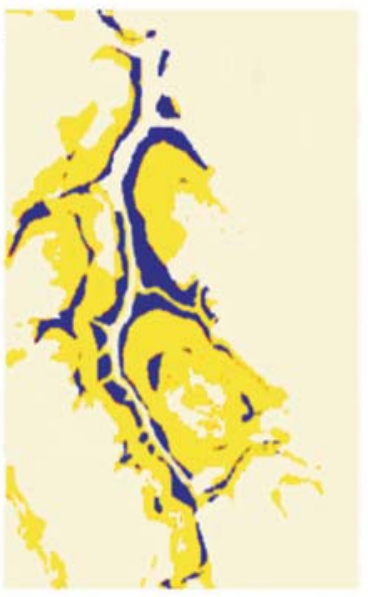

0

4.096
A. Neossolo Litólico

B. Gleissolo

C. Neossolo Flúvico

D. Argissolo Acinzentado

E. Cambissolo

F. Latossolo Vermelho-Amarelo

G. Espodossolo 


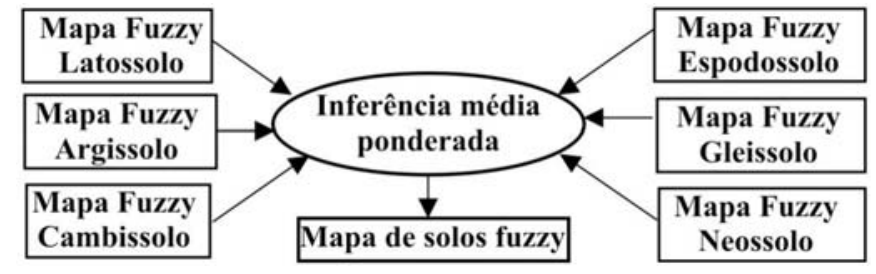

Figura 7. Fluxograma do processo de geração do mapa de solo digital

Este resultado foi interpretado como decorrente de variações locais impostas por um ou mais fatores de formação considerados (geologia, vegetação, declividade e altitude). No mapa de solos digital, essas variações determinariam o aparecimento de novas "unidades" com características diferenciadas que não teriam encontrado representação espacial no mapa convencional de solos. As "novas unidades" podem corresponder a inclusões de solos existentes nas unidades ou a zonas de transição entre as classes de solos de unidades vizinhas; no último caso representam, no mapa

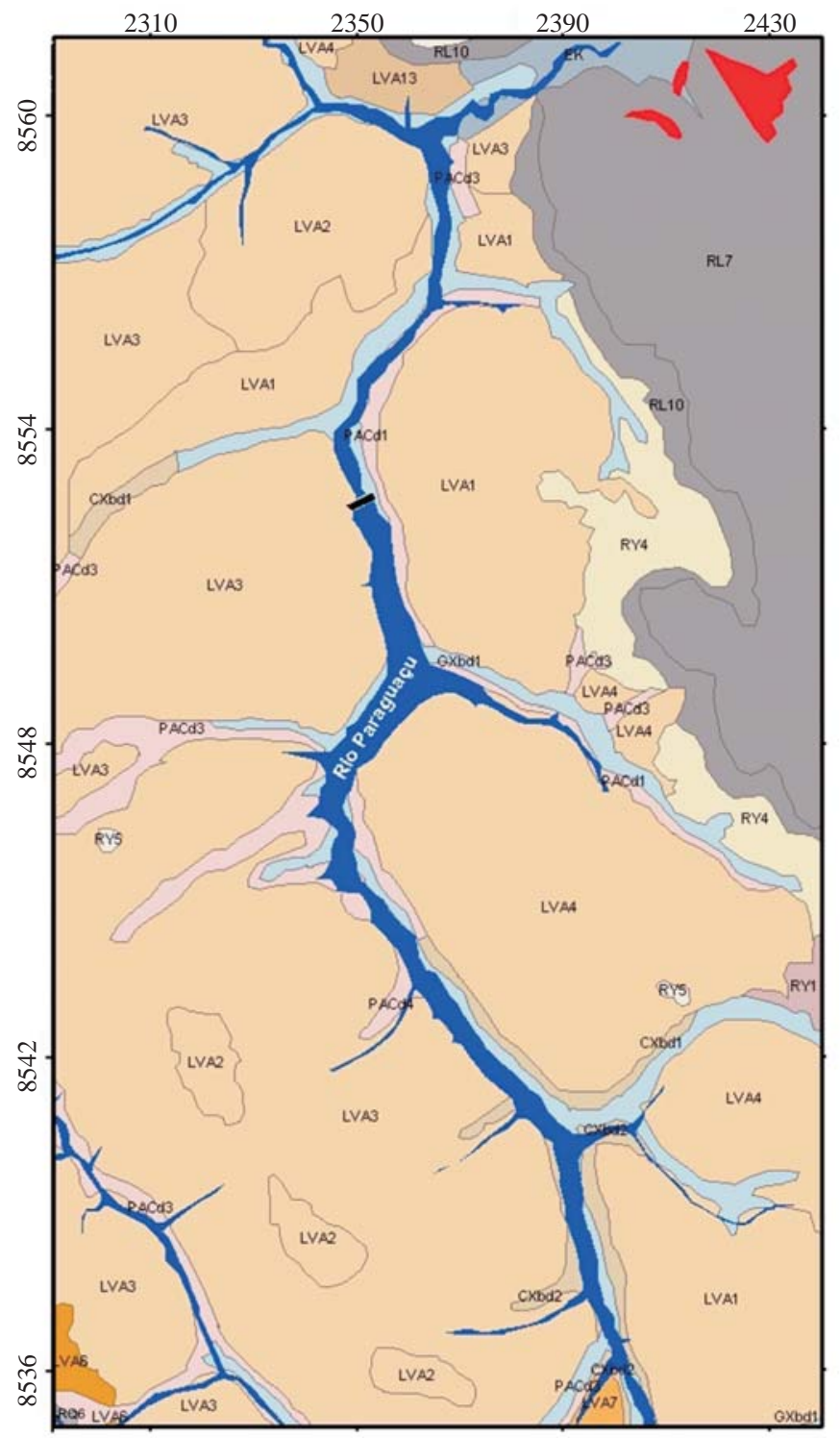

digital, a passagem progressiva de uma classe para outra, ou seja, zonas nas quais há, provavelmente, ocorrência de solos intergrades.

Constataram-se, na análise dos mapas convencional e digital de solos, algumas contradições relacionadas com a menor generalização no domínio de espaços (Zhu et al., 2001), determinada pelo tamanho do pixel utilizado na confecção do mapa digital e pela dificuldade de atualização dos solos do mapa convencional, devido à falta de acesso às descrições morfológicas e das análises físico-químicas dos componentes das unidades do mapa de solos convencional (utilizado como "verdade"); o que gerou enquadramentos divergentes entre o mapa de solo convencional e o digital. Um exemplo de incompatibilidade são as unidades de Argissolos Vermelho-Amarelos delineadas no mapa digital e que não existem no mapa convencional.

Outro ponto a ser considerado são os critérios estabelecidos para a área mínima mapeável que, conceitualmente, em mapas analógicos é determinada pelas menores dimensões que

\section{Mapa de solos da Região de Mucugê - BA}

\section{Legenda}

LVA1 Latossolo Vermelho Amarelo distrófico

LVA2 Latossolo Vermelho Amarelo distrófico

LVA3 Latossolo Vermelho Amarelo distrófico

LVA4 Latossolo Vermelho Amarelo distrófico

LVA6 Latossolo Vermelho Amarelo distrófico

LVA7 Latossolo Vermelho Amarelo distrófico

LVA13 Latossolo Vermelho Amarelo distrófico

LVA17 Latossolo Vermelho Amarelo distrófico

PAcdl Argissolo Acinzentado distrófico

PAcd3 Argissolo Acinzentado distrófico + Gleissolo Háplico

PAcd4 Argissolo Acinzentado distrófico + Neossolo Litólico

CXbd1 Cambissolo Háplico distrófico + Gleissolo Háplico

CXbd2 Cambissolo Háplico distrófico + Neossolo Litólico

EK Espodossolo Humilúvico

Gxbd1 Gleissolo Háplico distrófico + Organossolo Litólico

RL7 Neossolo Litólico + Neossolo Regolítico

RL10 Neossolo Litólico Húmico + Afloramento de Rocha

RQ6 Neossolo Quartzarênico Órtico

RY1 Neossolo Flúvico + Latossolo Vermelho Amarelo

RY4 Neossolo Flúvico + Afloramento de Rocha

RY5 Neossolo Flúvico

Mucugê $\square$ Rio Paraguaçu $=$ Barragem

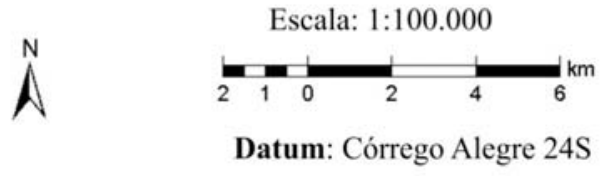

Fonte: Adaptado de IBGE, 1988. Diagnóstico dos Recursos Naturais da Bacia do Alto Paraguaçu. Relatório Interno 


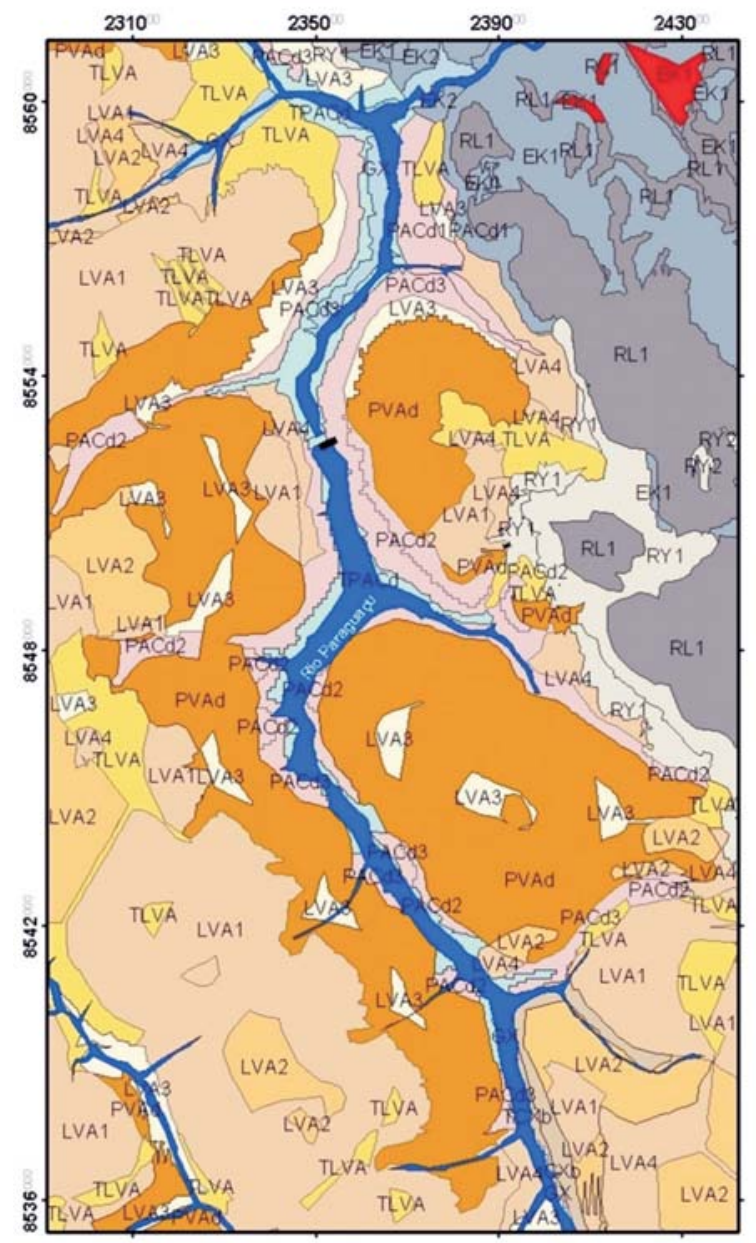

Mapa digital de solos da Região de Mucugê - BA

Legenda

- LVA1 Latossolo Vermelho Amarelo distrófico

LVA2 Latossolo Vermelho Amarelo distrófico

LVA3 Latossolo Vermelho Amarelo distrófico

- LVA4 Latossolo Vermelho Amarelo distrófico + Neossolo Flúvico

TLVA Latossolo Vermelho Amarelo / Argissolo Vermelho Amarelo distrófico

- PAcdl Argissolo Acinzentado distrófico

- Pacd2 Argissolo Acinzentado distrófico + Cambissolo Háplico distrófico

PAcd3 Argissolo Acinzentado distrófico + Gleissolo Háplico distrófico

PVAd Argissolo Vermelho Amarelo distrófico

T1 Transição Argissolo Acinzentado distrófico / Gleissolo Háplico

Cx1 Cambissolo Háplico distrófico

CX2 Transição Cambissolo Háplico / Gleissolo Háplico

EK1 Espodossolo Humilúvico + Afloramento de Rocha

EK2 Espodossolo Humilúvico + Gleissolo Háplico distrófico

GX Gleissolo Háplico distrófico

RY1 Neossolo Flúvico

RY2 Neossolo Flúvico + Neossolo Litólico

RL1 Neossolo Litólico + Afloramento de Rocha

- Mucugê = Rio Paraguaçu - Barragem

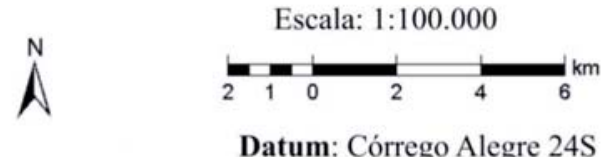

Figura 9. Mapa digital de solos gerado sob influência fuzzy da região de Mucugê, BA

podem ser legivelmente delineadas em um mapa de solos, sem prejuízo da informação gerada nos trabalhos de campo. Na prática, ela corresponde a uma área de $0,4 \mathrm{~cm}^{2}$. A equivalência desta área no mapa com a área correspondente no terreno, é função da escala final de apresentação que, em um mapa de escala 1:100.000, corresponde a 0,4 km² (FIBGE, 2005).

Em sua revisão bibliográfica sobre mapeamento digital de solo, McBratney et al. (2003), mostram que a escala cartográfica digital assume, para $1 \mathrm{~m}$ (comprimento lateral de 1000 pixel), que a menor área discernível é de 1 x $1 \mathrm{~mm}$, ou seja, 1 pixel. Considerando-se que o tamanho do pixel ( $\rho$ ) de um mapa convencional na escala 1:100.000 pode ser calculado como $\rho=1 / \chi \times \lambda$ e que a área mínima mapeável $(\lambda)$ na escala $(1 / \chi) 1: 100.000$ pode ser de $1 \times 1 \mathrm{~mm}$, $\rho$ seria igual a $100 \mathrm{~m}$; entretanto, para o processamento de sinais a resolução mínima deve corresponder à área de 2 x 2 pixels, tamanho padrão designado de resolução espacial nominal.

Embasados nos conceitos de área mínima mapeável e da resolução espacial nominal de 2 x 2 pixels propõe-se, para o mapa digital de solo da região de Mucugê, a partir do pixel de $30 \mathrm{~m}$ de resolução, um levantamento de reconhecimento com nível de alta intensidade com escala cartográfica de 1:50.000, com a seguinte correlação de resoluções e extensões que podem ser generalizadas para a aplicação no processo de confecção de mapas de digitais de solo (Tabela 2).
Tabela 2. Resolução e extensão para o mapa de solo digital

\begin{tabular}{ccccc}
\hline $\begin{array}{c}\text { Tamanho do } \\
\text { pixel }\end{array}$ & $\begin{array}{c}\text { Área mínima } \\
\text { mapeável }\end{array}$ & $\begin{array}{c}\text { Resolução } \\
\text { espacial } \\
\text { nominal }\end{array}$ & Extensão ${ }^{2}$ & $\begin{array}{c}\text { Escala } \\
\text { cartográfica }^{\text {sugerida }}\end{array}$ \\
$30 \mathrm{~m}$ & $\begin{array}{c}180 \times 180 \mathrm{~m} \\
=0,0324 \mathrm{~km}^{2}\end{array}$ & $60 \times 60 \mathrm{~m}$ & $3-300 \mathrm{~km}$ & $1: 50.000$ \\
\hline
\end{tabular}

${ }^{1}\left(0,6\right.$ x 0,6 cm); ${ }^{2}$ calculado com o mínimo de 100 e o máximo de 10.000 pixels

É preciso, entretanto, definir a aplicabilidade de um novo modelo para que a promessa tecnológica não seja incompatível com a real necessidade e possibilidade de utilização; recomenda-se, portanto, a repetição da metodologia em outras áreas que possuam mapas de solo convencionais de boa qualidade e visitas a campo após o processamento (obtenção do mapa em laboratório), para verificar a existência ou não das variações e confrontar as informações contidas no mapa convencional de solos com as do mapa gerado por esta metodologia.

No presente estudo, o valor de $0,1 \mathrm{~km}^{2}$ do terreno foi definido como área mínima mapeável para edição final do mapa digital de solo, haja vista que os testes mostraram que valores menores resultavam em um número muito elevado de classes que continham diversos componentes delineados em função de pequenas variações no terreno, provenientes de intervenções antrópicas (canais de irrigação e zonas de 
empréstimo, por exemplo) e que, durante o processamento, eram interpretados como variações no relevo; considerou-se, também, para esta definição, a impossibilidade prática de se checar um grande número de informações derivadas (componentes) e a necessidade de se estabelecer parâmetros de comparação entre escala e a área mínima mapeável do mapa convencional e a do digital de solo.

Este valor permitiu eliminar delineamentos resultantes de interferências (aparecimento de "falsos componentes") e adequar os resultados à realidade dos trabalhos de campo, de forma a propiciar a validação final (certificação em campo da existência dos componentes delineados no mapa digital e não encontrados no mapa convencional) e à adição de informações específicas para cada unidade (dados morfológicos e físico-químicos), que atendam às exigências de levantamentos na escala proposta para o mapa digital.

Sabe-se que as unidades de mapeamento constituem um conjunto de áreas de solos, com posições e relações definidas na paisagem e que são caracterizadas em termos da(s) unidade(s) taxonômica(s) que a(s) compõe(m); logo, a utilização de dados com melhor resolução proporcionará a identificação de unidades mais homogêneas que as existentes no mapa convencional, cuja individualização foi possibilitada no mapa digital pela adição de dados de relevo em maior escala.

A integração de MDT com pixel de 30 m permitiu maior refinamento no delineamento de unidades de mapeamento e maior pureza e precisão das informações vinculadas. Ressalta-se que os dados de vegetação e geologia utilizados provieram de mapas 1:100.000 e que as informações extraídas dentro da metodologia convencional de levantamentos de solo são compatíveis com a escala 1:50.000 (FIBGE, 2005), sugerida para o mapa digital de solos da Região de Mucugê.

A ampliação da escala pode propiciar a transformação de inclusões (áreas de solo em proporção muito menor que o componente ou componentes principais), em unidades simples, ou sua integração e delineamento em novas unidades combinadas ou, ainda, a individualização de associações de solos em unidades simples, já que passariam a ter maior representatividade. Em outras palavras, unidades que sofreram generalização no domínio de espaço (Zhu at al., 2001; Zhu, 2000), isto é, que a princípio não eram mapeáveis na escala 1:100.000, puderam ser delineadas no mapa digital.

Partindo deste princípio, os delineamentos de unidades no mapa digital que não encontraram, no mapa de solo tradicional, correspondências, são explicados pelo fato de que esses componentes não puderem registrar, durante a filtragem determinada pela escala, no mapa convencional, seus locais e espaços e acabaram sendo incorporados à unidades centrais; já no mapa digital surgem os registros, o que implica em redução da generalização no domínio de parâmetros e espaço, ou seja, em adição de informação que no mapa tradicional seria descartada em função das generalizações impostas pela escala.

Outro ponto a se considerar, é que a confecção de mapa digital de solos, segundo a metodologia proposta exige, acima de tudo, que os conceitos relativos à concepção do mapa de solos (forma de "apresentação" - visualização das unidades e seus componentes), sejam reconstruídos pois o especialista, ao fornecer informações para a composição das classes de possibilidades, alimenta o sistema com conjunto de dados e informações relacionados à transição de solos (discretização) e vinculadas a pequenas áreas que ele conhece e que estão mais de acordo com a forma de distribuição da cobertura pedológica na natureza; entretanto, o modelo convencional de mapas de solo não comporta esta forma de representação, dada a prática da cartografia baseada em polígonos (Booleana) e engessada pelos critérios de área mínima mapeável determinados pelas escalas para a representação das unidades e, como conseqüência, ocorre tendência na construção de mapas digitais gerados sob inferência fuzzy ao aparecimento de áreas que estariam relacionadas a zonas de transição entre duas ou mais unidades de solo e ao delineamento de áreas inexistentes no mapa convencional.

Ressalta-se que os mapas digital e convencional de solos possuem, neste trabalho, a mesma escala e que algumas das diferenças existentes podem ter derivado da finalidade do mapa convencional, fato que pode ter determinado menor qualidade das informações espaciais vinculadas.

\section{CONCLUSÕES}

Pode-se constatar que a metodologia proposta para mapeamento de solos utilizando a interferência fuzzy possibilitou:

1. Gerar mapas digitais de solos com refinamento da escala e fazer predição de unidades a partir de dados auxiliares (relacionados aos fatores de formação do solo) preexistentes e do conhecimento de especialistas de solos.

2. Menor generalização das classes de solo no domínio de espaço e parâmetros, pois o formato do mapa permite agregar informações inerentes a condições particulares da cobertura pedológica de determinada região, já que na modelagem SIG os dados raster de uma área podem ser representados por muitos quadrados pequenos - "pixels”, cujas dimensões permitem a representação de pequenas variações com boa resolução espacial.

3. Operacionalização dos trabalhos de campo com redução das etapas, visto que a validação do mapa seria realizada em pontos geograficamente bem definidos para constatação das unidades, descrição e caracterização da(s) classe(s) de solo(s) componente(s) da(s) mesma(s).

4. Agilizar o processo de atualização futura de mapas pela facilidade de integração de informações que podem subsidiar o gerenciamento e a preservação dos recursos naturais.

5. A metodologia é extremamente dependente do conhecimento de especialistas em solos da área a ser mapeada e, como já citado na literatura por alguns autores, da qualidade do banco de dados. 


\section{LITERATURA CITADA}

Bigarella, J. J.; Becker, R. D. E.; Santos, G. F. Estrutura e origem das paisagens tropicais e subtropicais. Fundamentos geológico geográficos, alterações químicas e físicas das rochas relevo cárstico e dômico. Florianópolis: UFSC, 1994, v.1, 425p.

Brasil - Ministério das Minas e Energia. Secretaria Geral. Projeto RADAMBRASIL Folha SD-24 Baia de Todos os Santos. Geologia, geomorfologia, pedologia, vegetação e uso potencial da terra. 4.ed., Rio de Janeiro, 1976. 594p.

CPRM - Companhia de Pesquisa de Recursos Minerais. Programa levantamentos geológicos do Brasil: Carta geológica. Escala 1:100.000 (Folha SD24-V-C-II Mucugê) Estado da Bahia. Pedreira, A. J.; Martins Martagalho, R. de S. F. X. (org). Brasília: DNPM/CPRM, 1990. 122p.

CPRM - Companhia de Pesquisa de Recursos Minerais. Projeto Chapada Diamantina: Parque Nacional da Chapada Diamantina, BA: Informações básicas para a gestão territorial: Diagnóstico do meio físico e da vegetação. Salvador: CPRM/IBAMA, 1994. 104p.

ESRI - Using the ArcView. Redlands: ESRI Press, 1999a. 340p.

ESRI - Using the ArcView Spatial Analyst. Redlands: ESRI Press, 1999b. 240p.

FIBGE - Fundação Instituto Brasileiro de Geografia e Estatística. Diagnóstico dos recursos naturais da bacia do Alto Paraguaçu: mapas de vegetação, solos na escala 1:100.000 Relatório interno. Salvador: IBGE, 1988. 78p.

FIBGE - Fundação Instituto Brasileiro de Geografia e Estatística. Manual técnico de pedologia. Coordenação de Recursos Naturais e Estudos Ambientais. 2.ed. Rio de Janeiro: IBGE, 2005. 300p. Manuais técnicos em geociências, n. 4.
Hudson, B. D. The soil survey as paradigm-based science. Soil Science Society of American Journal, v.56, p.836841. 1992.

Jenny, H. E. W. Hilgard and the birth of modern soil science. Berkeley: Farallo Publication. 1961. 144p.

McBratney, A. B.; Mendonça Santos, M. L.; Minasny, B. On digital soil mapping. Geoderma, v.117, p.3-52, 2003.

Sawatzky, D. L.; Raines, G. L.; Bonham-Carter, G. F.; Looney, C. G. ArcSDM2: ArcMAP extension for spatial data modelling using weighets of evidence, logistic, regression, fuzzy logic and neural network analysis. 2004. http://www.ntserv.gis,nrcan,gc.ca/ sdm. 05 Abr. 2006.

SEI - Superintendência de Estudos Econômicos e Sociais da Bahia. Atributos climáticos do Estado da Bahia. Salvador: SEI. 1998. 85p. Série estudos e pesquisas, n.38.

Tanscheit, R. Fundamentos da lógica Fuzzy e controle Fuzzy. http://www.ica.ele.puc-rio.br/cursos/download/SILogica_Controle_Fuzzy.pdf. 05 Abr. 2006.

Zhu, A. X. A personal construct-based knowledge acquisition process for natural resource mapping using GIS. International Journal of Geographical Information Science, v.13, n.2, p.119-141. 1999.

Zhu, A. X. Mapping soil landscape as spatial continua: The neural network approach. Water Resources Research, v.36, p.663677. 2000.

Zhu, A. X.; Band, L. E.; Vertessy, R.; Dutton, B. Deriving soil property using a soil land inference model (SoLIM). Soil Science Society of American Journal, v.61, p.523-533. 1997.

Zhu, A. X.; Hudson, B.; Burt, J.; Lubich, K.; Simonson, D. Soil mapping using GIS, expert knowledge, and fuzzy logic. Soil Science Society of American Journal, v.65, p.885-894, 2001. 